\title{
Tecnologias de Armazenamento Térmico para Plantas CSP no Semiárido Brasileiro
}

Thermal Storage Technologies for CSP Plants in the Brazilian Semi-arid

Mateus Telles Nébias'1 orcid.org/0000-0001-6458-1375

Alcides Codeceira Neto' ${ }^{1}$ orcid.org/0000-0001-6529-4925

${ }^{1}$ Escola Politécnica de Pernambuco, Universidade de Pernambuco, Recife, Brasil

E-mail do autor principal: Mateus Nébias engmateusnebias@gmail.com

\section{RESUMO}

A nova era da energia solar vem com o modelo termoelétrico que abre um novo horizonte nas energias renováveis. O semiárido brasileiro tem condições geográficas que favorecem esse tipo de instalações dada sua alta taxa de insolação por dia. Nessa região em especial, pode-se pensar em criar termoelétricas despacháveis. Para tal fim, as usinas usariam a tecnologia de armazenamento térmico, que as tornariam aptas a seguir alimentando o SIN, Sistema Integrado Nacional, mesmo sem a incidência de luz solar. No intuito de entender melhor como aproveitar da melhor maneira possível essa riqueza natural, esse trabalho mostra as vantagens do semiárido brasileiro e, aliado a isso, as tecnologias disponíveis de armazenamento térmico e como elas poderiam ser empregadas na geração de energia elétrica de maneira despachável.

PALAVRAS-CHAVE: Energias renováveis; Armazenamento térmico; CSP; Semiárido;

\section{ABSTRACT}

The new era of solar energy comes with the thermoelectric model wich opens a new horizon in renewable energies. The Brazilian semiarid has geographical conditions that favor this type of installations given its high insolation rate per day. In this particular region, one can think of creating dispatchable thermoelectric plants. To this end, the plants would use the thermal storage technology, which would make them able to continue to feed SIN even without the incidence of sunlight. In order to better understand how to make the most of this natural wealth, this work will show the advantages of the Brazilian semi-arid and, together with the available thermal storage technologies and how they could be used to generate electricity in a dispatchable manner.

KEY-WORDS: Renewable energies; Thermal storage; CSP; semi-arid; 


\section{INTRODUÇÃO}

A matriz energética brasileira sempre foi predominantemente baseada em fontes renováveis. Dentre elas, destaca-se a geração hidráulica correspondendo a $68,1 \%$ da oferta interna no período 2017-2016 segundo relatório da EPE, Empresa de Pesquisa Energética. Nesse mesmo relatório, temos que a capacidade total instalada de geração de energia elétrica do Brasil (centrais de serviço público e autoprodutoras) alcançou 150.338 MW, crescimento de $9.479 \mathrm{MW}$, onde usinas eólicas e solares (especialmente as eólicas) foram responsáveis por $26,3 \%$ de aumento da malha nacional. Fica evidente aí uma tendência de mudança no perfil da geração de energia no território nacional, especialmente no que se refere às renováveis. Mesmo com a energia eólica ocupando local de destaque nesse novo momento da geração energética renovável, é interessante ao país diversificar sua matriz energética o máximo possível por diversas razões. Assim sendo, a energia solar, especialmente as de CSP, do inglês, usina de concentração solar, tem papel fundamental [1].

Países como Estados Unidos e Espanha são atualmente potência no setor de geração energética usando usinas CSP correspondendo a $90 \%$ da capacidade atual instalada de geração em usinas no mundo. Entretanto, não são somente eles que fazem uso dessa fonte, países como Emirados Árabes, Índia, China, Israel e tantos outros se valem dessa fonte que, na presença de um ambiente favorável, torna-se tão eficiente e competitiva como todas as outras fontes renováveis. Algumas dessas usinas são definidas como híbridas, que é quando, na ausência de incidência de luz solar suficiente para aquecer seu fluido de transporte térmico, se valem da queima de algum combustível para seguirem gerando. Outras, mais amigáveis ao meio ambiente, usam o armazenamento térmico que, na ausência de incidência de luz solar suficiente para aquecer seu fluido de transporte térmico, usam o fluido já aquecido que ficou armazenado ou atravessam seu fluido em um armazenamento térmico que se encarregará de aquecer tal fluido [2].

O semiárido brasileiro compreende uma área de $969.589 \mathrm{~km}^{2}$. Essa área se divide entre os Estados do Ceará e Rio Grande do Norte quase que integralmente, a maior parte da Paraíba e Pernambuco, Sudeste do Piauí, Oeste de Alagoas e Sergipe, região central da Bahia e uma faixa que se estende em Minas Gerais, como mostrado na figura 1. Assim sendo, mesmo sendo uma região de características semelhantes, dada sua extensão, ainda se pode encontrar regiões que não sejam tão homogêneas com o resto. $O$ que ocorre nessas áreas é a presença de um microclima específico, que se dão pela presença de serras e montanhas, como é o caso da Chapada Diamantina, na Bahia, parte Oeste da Paraíba e no Centro-norte de Pernambuco [3].

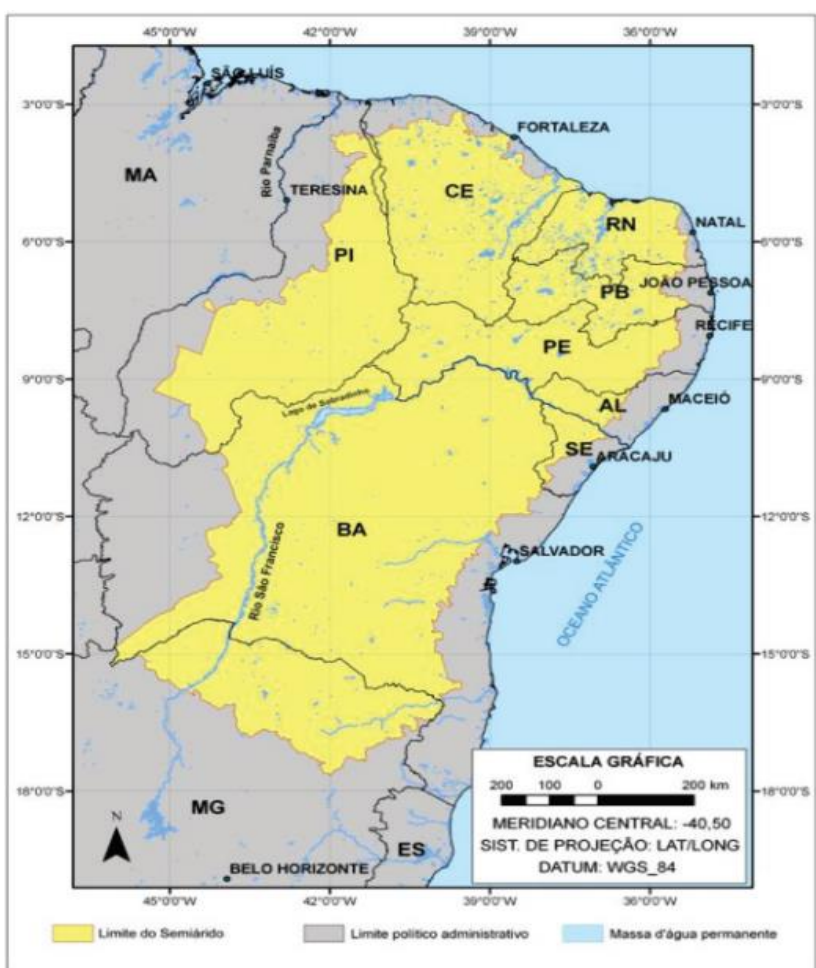

Figura 1: Delimitação do Semiárido brasileiro. Fonte: (Base cartográfica: IBGE, 2010)

Nas seções seguintes apresentaremos as características que tornam essa região tão vantajosa e também as tecnologias disponíveis de armazenamento térmico hoje no mundo.

\section{O SEMIÁRIDO BRASILEIRO}

Um fator climático de extrema importância quando se fala sobre a instalação de uma usina solar é a quantidade de chuvas que aquela região recebe. Próximo ao litoral leste, as chuvas são superiores a $1.000 \mathrm{~mm}$ por ano e, à medida que se vai adentrando a região, atravessando o Agreste e se dirigindo para o Sertão, as precipitações diminuem e alcançam valores médios inferiores a $500 \mathrm{~mm}$ anuais. Índices baixos assim de precipitação anual são um bom indicativo no que diz respeito à pluviosidade na 
região. $O$ deslocamento dessas massas em direção ao continente faz com que elas vão perdendo umidade $e$, por consequência, diminuindo suas dimensões. Com isso, o semiárido tende a ser um local com poucas nuvens, especialmente, nas áreas fronteiriças entre os Estados de Pernambuco, Bahia e Piauí, como mostrado na figura 2, tendo assim um menor sombreamento ao longo do ano, o que implica em maior disponibilidade para as plantas solares ali instaladas. Como em algumas usinas o fluido de transporte térmico é a água, essa região ainda se beneficia da presença do rio São Francisco e seus afluentes, de onde podem, numa eventual necessidade, captar a água para usar em seu ciclo de troca e calor [3].

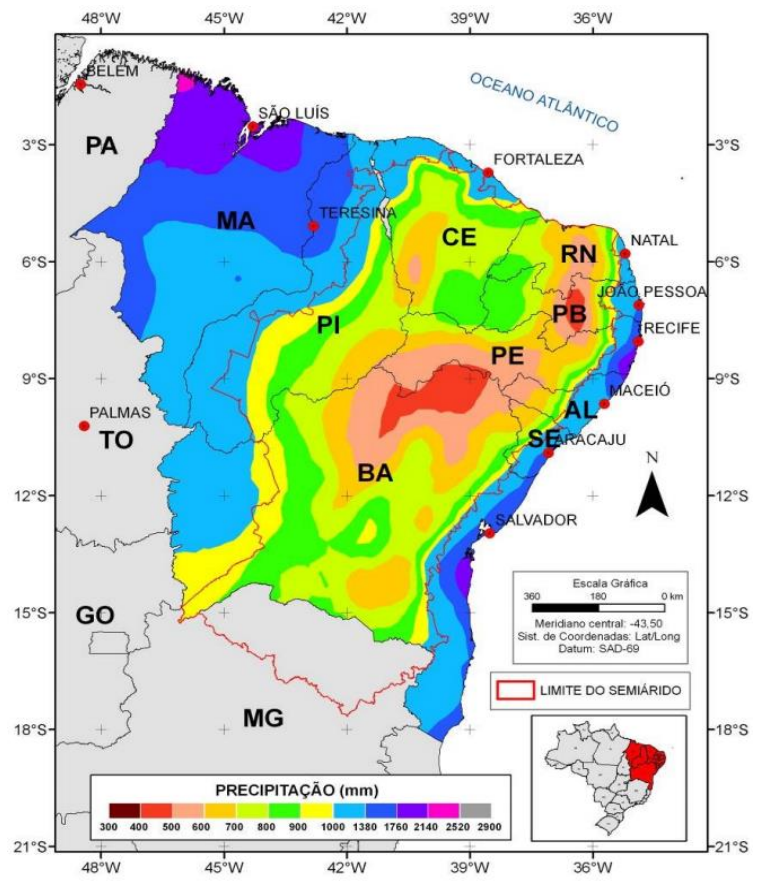

Figura 2: Delimitação do Semiárido brasileiro. Fonte: (Base cartográfica: IBGE, 2010).

Como a fonte exclusiva de energia numa planta solar com armazenamento térmico, portanto não híbrida, vem da luz do Sol, o dado mais importante que deve ser analisado quando se quer instalar uma planta é a irradiação solar. Os parâmetros usados para essa avaliação são: insolação diária, como mostrado na figura 3, e radiação solar, como mostrado na figura 4, que, respectivamente, informam a disponibilidade diária do Sol e a potência que a irradiação solar entrega naquela área.

Pelas imagens do Atlas pode-se notar que a região nordeste é muito favorecida no que diz respeito à incidência solar. Dados mais apurados de irradiação solar direta dessa área mostram que especialmente o semiárido nordestino oferece 0 ambiente perfeito para plantas de geração solar. $O$ que se deve levar em conta também nesse dado é a sazonalidade dessa insolação. Como se pode ver existem meses, como Janeiro, onde a irradiação solar direta é mais baixa, e meses como Julho, onde a irradiação direta é altíssima, como visto na figura 5 [4].

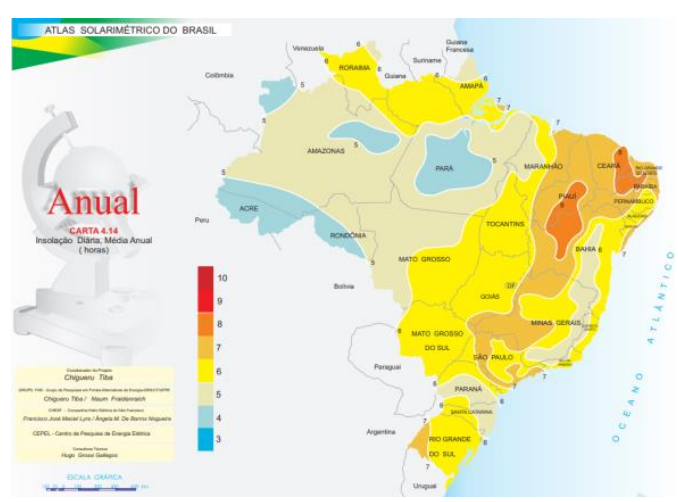

Figura 3: Mapa de insolação diária, média anual (horas).

Fonte: Atlas Solarimétrico do Brasil, 2010.

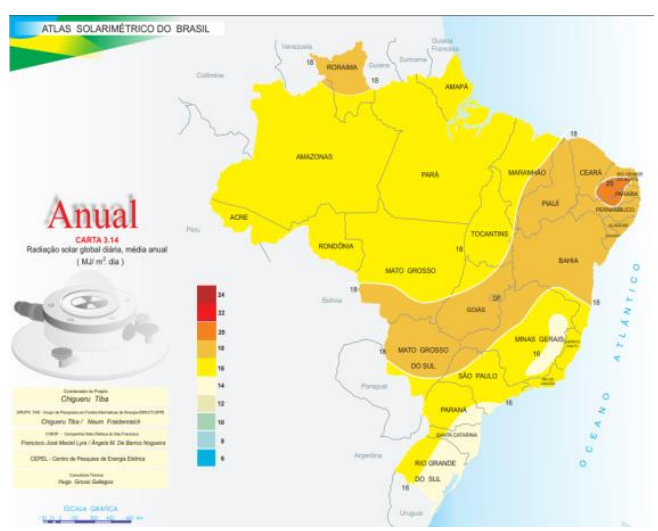

Figura 4: Mapa de radiação solar global diária, média anual $\left(\mathrm{MJ} / \mathrm{m}^{2}\right.$.dia).

Fonte: Atlas Solarimétrico do Brasil, 2010. 


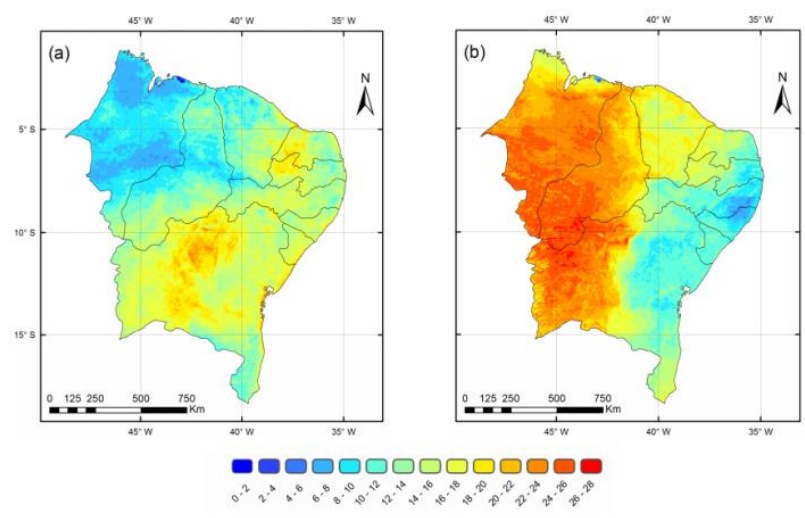

Figura 5: Distribuição espacial da irradiação solar direta normal média mensal $\left(\mathrm{MJ}^{-2} \mathrm{~m}^{-2}\right.$ ): (a) Janeiro e (b) Julho de 2008.

Fonte: Atlas Solarimétrico do Brasil, 2010.

Para finalizar os critérios de análise no que diz respeito à qualidade da irradiação na área, outro indicativo que favorece o semiárido nordestino é a distribuição de frequência da transmissividade atmosférica diária, também conhecida como índice de claridade (Kt). Esse índice é a relação dada entre irradiação solar horizontal medida na localidade em estudo e a irradiação solar diária extraterrestre. Como exemplo, pode-se notar pelo Kt de Arcoverde, Mesorregião do sertão pernambucano, como pode ser visto na figura 6 , localizada no agreste de Pernambuco, que o semiárido tem sempre uma alta relação de transmissividade atmosférica [5].

\section{PLANTAS HELIOTÉRMICAS CSP}

Agora que já foi mostrado como é favorável a instalação de uma planta CSP no semiárido, podese falar sobre as tecnologias disponíveis de armazenamento e de como isso seria interessante tanto para o país como para o empresariado que eventualmente investisse nessa forma de geração.

Do ponto de vista de instalação, as CSP são realmente caras. Mas esse custo é severamente amortizado pelo fato de, no caso do armazenamento térmico, os custos com combustível serem praticamente nulos. Por exemplo, no caso de uma termoelétrica de calhas parabólicas sem armazenamento de energia térmica, tem-se custos de capital de USD4.600/kW com um fator de capacidade entre 0,2 e 0,25 .

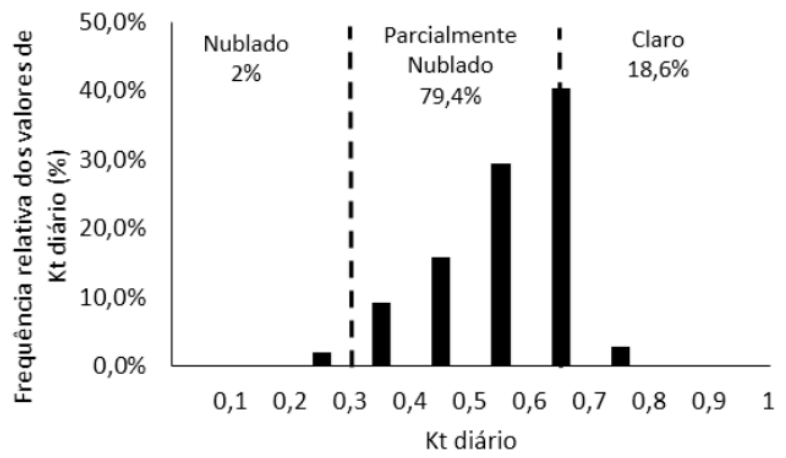

Figura 6: Distribuição de frequência de $\mathrm{Kt}$ e a frequência de dias de céu claro, nublado e parcialmente claro (Análise da Tendência da Irradiação Solar e Temperatura Ambiente no Agreste Nordestino Empregando Dados Medidos de Longo Prazo).

Já, quando se adiciona um armazenamento térmico equivalente a seis horas de operação da planta, tem-se os custos de instalação entre USD 7.100/kW e USD 9.800/kW, mas permite-se que os fatores de capacidade sejam duplicados [2].

Já no caso das torres solares, a temperatura que se pode atingir é ainda maior que nas calhas parabólicas. Essa vantagem térmica acaba por fazer essa tecnologia ser a mais promissora para o futuro dessa forma de geração pois podem atingir temperaturas muito altas com perdas gerenciáveis usando sal fundido como fluido de transferência de calor. Isso permitirá temperaturas operacionais mais altas e a eficiência do ciclo de vapor, além de reduzir o custo de armazenamento de energia térmica, permitindo um diferencial de temperatura mais alto. A instalação de termoelétricas de torres solares com armazenamento térmico entre 6 e 15 horas podem custar entre USD 6.300 e USD $10.500 / \mathrm{kW}$ e podem atingir fatores de capacidade de 0,40 a até 0,80 [2].

A tabela 1, de maneira resumida, mostra como é essa relação de custo não só de instalação como também de O\&M (operação e manutenção) e LCOE (custo nivelado da eletricidade) para plantas heliotérmicas com e sem armazenamento térmico para as tecnologias de calha parabólica e torre solar. 
Tabela 1: Custo e performance de plantas CSP em 2011(Concentrating Solar Power).

\begin{tabular}{|c|c|c|}
\hline \multicolumn{3}{|c|}{ Calha Parabólica } \\
\hline & $\begin{array}{l}\text { Sem } \\
\text { Armazenamento }\end{array}$ & $\begin{array}{ll}6 \mathrm{~h} & \mathrm{de} \\
\text { Armazenamento }\end{array}$ \\
\hline $\begin{array}{ll}\text { Custo } & \text { de } \\
\text { instalação } & \\
(2010 & \\
\text { USD/kW) } & \end{array}$ & 4600 & 7100 a 9800 \\
\hline $\begin{array}{l}\text { Fator } \text { de } \\
\text { capacidade } \\
(\%)\end{array}$ & 20 a 25 & 40 a 53 \\
\hline $\begin{array}{l}\text { O\&M } \quad(2010 \\
\text { USD/kWh) }\end{array}$ & 0.02 a 0.035 & 0.02 a 0.035 \\
\hline $\begin{array}{l}\operatorname{LCOE}(2010 \\
\text { USD/kWh) }\end{array}$ & 0.14 a 0.16 & 0.14 a 0.16 \\
\hline \multicolumn{3}{|c|}{ Torre Solar } \\
\hline & $\begin{array}{lcc}6 & \text { a } & 7.5 \mathrm{~h} \\
\text { Armazenamento }\end{array}$ & 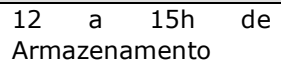 \\
\hline $\begin{array}{ll}\text { Custo } & \text { de } \\
\text { instalação } & \\
(2010 & \\
\text { USD/kW) } & \end{array}$ & 6300 a 7500 & 900 a 10500 \\
\hline $\begin{array}{l}\text { Fator } \text { de } \\
\text { capacidade } \\
(\%)\end{array}$ & 40 a 45 & 65 a 80 \\
\hline $\begin{array}{l}\text { O\&M } \quad(2010 \\
\text { USD/kWh })\end{array}$ & 0.02 a 0.035 & 0.02 a 0.035 \\
\hline $\begin{array}{l}\text { LCOE(2010 } \\
\text { USD/kWh) }\end{array}$ & 0.17 a 0.29 & 0.17 a 0.29 \\
\hline
\end{tabular}

Segundo as informações apresentadas, o armazenamento térmico não é um mero aditivo que pode ser colocado ou não numa usina heliotérmica. Ele é de fundamental importância para que a planta tenha competitividade e que, em situações muito favoráveis, ela possa ter tamanha disponibilidade que possa ser despachada como uma térmica convencional de óleo ou gás, por exemplo.

Como informação adicional para aumentar o leque de informação sobre essas duas tecnologias de preferência para plantas heliotérmicas (calha parabólica e torre solar), apresenta-se a Tabela 2, onde vários aspectos de ambas as tecnologias são comparadas.

\section{ARMAZENAMENTO TÉRMICO}

O armazenamento térmico, sob análise mais simples, nada mais é que uma maneira de estocar energia na sua forma térmica para depois se converter essa energia em sua forma elétrica.

Para isso, parte do fluido de transporte térmico advindo do campo solar, portanto já aquecido, é desviado para um tanque de armazenamento, o que se dá o nome de armazenamento de calor ativo direto, ou para um trocador de calor que aquecerá um fluido para armazenamento térmico, o que se dá o nome de armazenamento de calor ativo indireto [6].

$O$ fator usado para determinar 0 dimensionamento do campo solar, portanto, é de fundamental importância na hora de se desenvolver o projeto de uma planta heliotérmica com armazenamento térmico. Esse fator é chamado de Múltiplo Solar (MS). Para ter-se um correto dimensionamento do campo solar de uma planta, deve-se levar em conta o MS e a potência nominal da planta. Um campo solar grande demais pode gerar em excesso em condições de alta irradiação solar, enquanto campo pequeno fará com que o bloco de potência não opere em condições de plena carga.

No primeiro caso tem-se um superdimensionamento, que encarece o projeto e desperdiça a energia térmica excedente caso ela não seja armazenada e, no segundo caso, tem se um subdimensionamento, que faz com que a planta atenda de maneira parcial à carga. A Figura 7 traz um gráfico mostrando o impacto do MS e do armazenamento térmico no $\mathrm{LCOE}$, leave bleize cost of energy, que, traduzido do inglês, nada mais é do que o custo nivelado da energia [6].

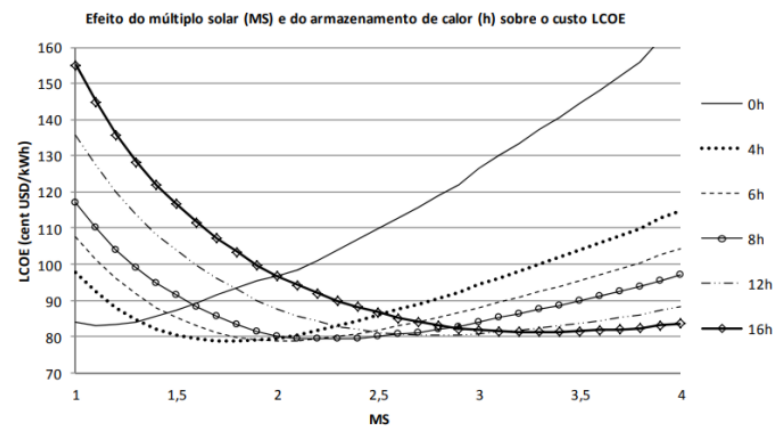

Figura 7: Impacto do MS e do armazenamento térmico no LCOE.

Fonte: Revista Brasileira de Energia Solar Volume V Número1, Jul 2014.

\section{TECNOLOGIAS DE ARMAZENAMENTO TÉRMICO}

No que diz respeito às tecnologias disponíveis de armazenamento térmico para plantas heliotérmicas CSP, algumas se destacam. São elas 0 armazenamento de sal fundido, 0 armazenamento Ruth e o armazenamento usando concreto. Por mais que essas sejam tecnologias já existentes, muito se pesquisa ainda sobre elas para reduzir os custos do sistema através de 
valores mais altos de temperatura que por sua vez aumentarão a eficiência do sistema. Para uma faixa de temperatura maior, se tem maior densidade de energia para o armazenamento, o que resulta em redução de custos para o material de armazenamento [7].

\subsection{Armazenamento de Sal Fundido}

Quando se fala de novos sais para se usar como fluido de armazenamento térmico no ambiente de geração de energia, a área mais promissora é toda a família de nitratos e nitritos e todos os tipos de misturas que possam ser feitas com eles. O objetivo é sempre aplicar uma faixa de temperatura operacional estendida para sais fundidos, a fim de diminuir os limites de temperatura mais baixos. Essa não é uma tarefa muito simples porque a economia de custos causada pelo aumento da densidade de energia tem que competir com custos adicionais devido ao aumento do custo de material para novas misturas de sal tecnicamente sofisticadas. Adicionalmente, ainda precisa-se analisar a possibilidade de se encontrar tais sais comercialmente e com ampla oferta. O foco das várias pesquisas feitas com sais é mudar a característica do fluido de armazenamento térmico sem perder a estabilidade química para altas temperaturas [7].

O melhor layout para esse tipo de tecnologia é o de tanque de armazenamento único. Nele estão armazenados tanto o fluido em baixa como o fluido em alta temperatura. O seu funcionamento, como mostrado na figura 8 , se dá, no processo de aquecimento, com o fluido em baixa temperatura deixando o tanque, sendo aquecido e regressando ao tanque, agora na porção aquecida do armazenamento.
Tabela 2: Comparação das duas principais tecnologias CSP (Concentrating Solar Power).

\begin{tabular}{|c|c|c|}
\hline & Calha Parabólica & Torre Solar \\
\hline Capacidade Típica & $10-300$ & $10-200$ \\
\hline $\begin{array}{l}\text { Maturidade } \quad \text { da } \\
\text { Tecnologia }\end{array}$ & $\begin{array}{l}\text { Atestada } \\
\text { Comercialmente }\end{array}$ & $\begin{array}{l}\text { Projetos-Piloto } \\
\text { Comerciais }\end{array}$ \\
\hline $\begin{array}{ll}\text { Temperatuda } & \text { de } \\
\text { Operação }(C) & \end{array}$ & $350-550$ & $250-565$ \\
\hline $\begin{array}{l}\text { Pico de eficiência da } \\
\text { Planta (\%) }\end{array}$ & 14-20 & $23-35$ \\
\hline $\begin{array}{l}\text { Eficiência } \quad \text { Solar- } \\
\text { Elétrica Anual }(\%)\end{array}$ & $11-16$ & $7-20$ \\
\hline $\begin{array}{l}\text { Fator de Capacidade } \\
\text { Anual }(\%)\end{array}$ & $\begin{array}{l}25-28 \quad \text { (sem } \\
\text { armazenamento) } \\
29-43 \quad \text { (com } \\
\text { armazenamento }\end{array}$ & $\begin{array}{lr}55 \quad(\text { com dez } \\
\text { horas de } \\
\text { armazenamento) }\end{array}$ \\
\hline $\begin{array}{l}\text { Concentração do } \\
\text { Coletor }\end{array}$ & 70-80 Sóis & >1000 Sóis \\
\hline $\begin{array}{l}\text { Condição do Vapor } \\
\text { (C/bar) }\end{array}$ & 380 a $540 / 100$ & $540 / 100$ a 160 \\
\hline $\begin{array}{l}\text { Demanda de água } \\
\left(\mathrm{m}^{3} / \mathrm{MWh}\right)\end{array}$ & $0.3-3$ & $0.25-3$ \\
\hline $\begin{array}{ll}\text { Adequação } & a \\
\text { Refrigeração a Ar } & \end{array}$ & Baixo para Bom & Bom \\
\hline $\begin{array}{l}\text { Armazenamento com } \\
\text { Sal Fundido }\end{array}$ & $\begin{array}{l}\text { Disponível } \\
\text { Comercialmente }\end{array}$ & $\begin{array}{l}\text { Disponível } \\
\text { Comercialmente }\end{array}$ \\
\hline
\end{tabular}

De maneira análoga, quando se quer descarregar $o$ tanque, 0 fluido em alta temperatura é bombeado para foda do tanque, troca calor e volta para o tanque, agora na porção de baixa temperatura do armazenamento [7].

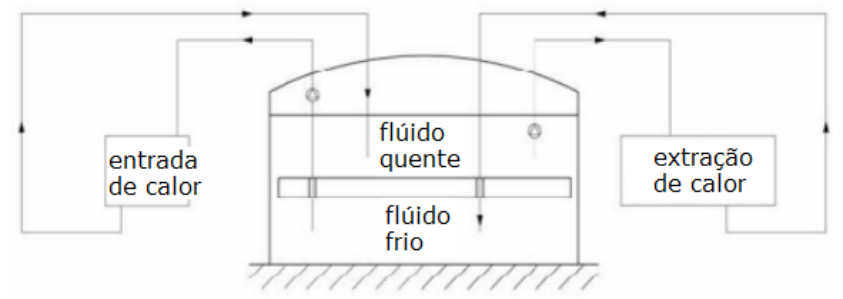

Figura 8: Projeto esquemático do sistema de armazenamento de tanque único com barreira de isolamento flutuante (Thermal Storage CSP Technology).

O desafio nesse modelo de tanque único reside na barreira de isolamento flutuante. Ao mesmo tempo em que a barreira precisa ser móvel para que os volumes superior e inferior possam variar de acordo com o funcionamento do armazenamento, ela também precisa ser suficientemente rígida para suportar a pressão do fluido ali armazenado. Assim sendo, a barreira deve ser composta de materiais resistentes à compressão, para assim se evitar qualquer 
problema com deformação ao se trabalhar com elevadas temperaturas. Mas, ao mesmo tempo que essa barreira é um desafio para a engenharia, a tecnologia de tanque único é um avanço nos custos da instalação. Em uma aplicação comercial do sistema de tanque único, uma redução das perdas térmicas de $50 \%$, que por consequência gera um aumento na sua eficiência, e dos custos de investimento, visto que agora não são construídos mais dois tanques e sim um, é esperada em comparação com a tecnologia de 2 tanques. Como vantagem adicional o armazenamento de tanque único está sempre preenchido, e então é possível usar bombas convencionais. Já na tecnologia de 2 tanques são necessárias bombas especiais de eixo vertical para trabalhar com tanques pressurizados que são mais caras, o que resulta em uma redução adicional de custo de instalação das plantas [7].

\subsection{Armazenamento Ruth}

Diferente da tecnologia de sal fundido, essa forma de armazenamento já atingiu o que pode ser sua forma final. Nessa modalidade de armazenamento, vapor saturado é armazenado e fornecido para geração de energia. Uma forma de aumentar o ciclo vapor desse processo, um segundo armazenamento faz um superaquecimento do fluido (Figura 9) [7].

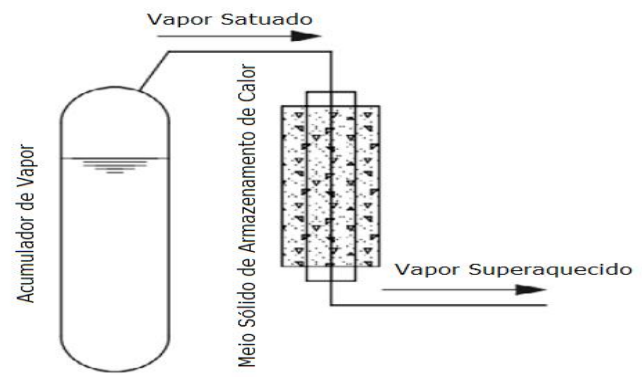

Figura 9: Acumulador de vapor com superaquecimento em sequência (Thermal Storage CSP Technology).

Esta é uma tecnologia de armazenamento que já é usada comercialmente na planta PS10 (Sevilha, Espanha) e fornece energia por 30 minutos à uma hora de operação extra. $O$ alto custo de tanques pressurizados para grandes volumes de vapor e capacidade de armazenamento faz com que essa tecnologia não seja muito viável. Assim sendo, o melhor uso dessa tecnologia é como armazenamento de buffer para um possível pico de demanda de energia [8].

\subsection{Armazenamento com Concreto}

Não tão madura como as duas tecnologias anteriores, o armazenamento fazendo uso de concreto está se tornando uma realidade e promete bons números no que diz respeito ao custo e à eficiência. Capaz de operar em temperaturas que variam entre $400^{\circ}$ e $500^{\circ}$ Celsius, ele está no range de atuação das termoelétricas. Em vez de se armazenar um fluido já aquecido para que se gere energia posteriormente, esse novo conceito armazena a energia térmica em módulos de concreto e, quando chega o momento de gerar energia, o fluido escoa por canos embutidos nesses módulos, como mostrado na figura 9, sendo assim aquecidos e gerando energia elétrica. Atualmente, o custo do investimento é de cerca de 30 euros por $\mathrm{kWh}$, mas se pretende chegar a valores de menos de 20 euros por kWh. Já existem instalações com essa tecnologia no mundo operando dois módulos de armazenamento que combinados geram 700kWh [8].

Ainda existem outras formas de armazenamento em estudo ao redor do mundo como é o caso doarmazenamento térmico com mudança de fase que ainda está em estágio experimental e consiste em usar os pontos de fusão e congelamento de sais como nitratos de sódio ou potássio para armazenar e fornecer calor para condensação e evaporação de vapor em plantas de vapor direto [9].

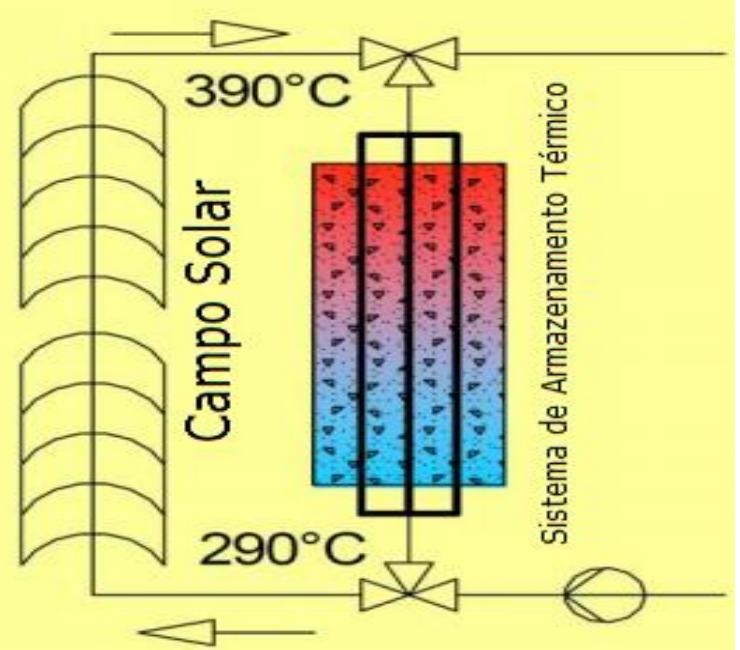

Figura 10: Esquema de armazenamento térmico usando módulos de concreto (Thermal Storage CSP Technology). 


\section{COMPARATIVO}

Agregando todas as informações que se têm disponíveis sobre as tecnologias de armazenamento térmico supracitadas, tem-se a tabela 3. Nenhuma das tecnologias é pesquisada no Brasil ainda, mas, mesmo assim, fora do país há muito campo e muito investimento nesse segmento de armazenamento térmico que se aplica não somente para geração de energia, mas também em processos industriais e até mesmo para dessalinização de água.

Tabela 3: Comparação entre as tecnologias de armazenamento térmico mais viáveis (ThermalStorage CSP Technology).

\begin{tabular}{|l|l|l|l|}
\hline & Sal Fundido & Ruth & Concreto \\
\hline $\begin{array}{l}\text { Densidade } \\
\text { Energética }\end{array}$ & Alta & Baixa & Média \\
\hline Custo & $\begin{array}{l}\text { Médio e caindo } \\
\text { devido às } \\
\text { pesquisas }\end{array}$ & $\begin{array}{l}\text { Alto devido aos } \\
\text { equipamentos } \\
\text { envolvidos no } \\
\text { armazenament } \\
\text { o }\end{array}$ & $\begin{array}{l}\text { Baixo devido ao } \\
\text { custo da } \\
\text { matéria-prima e } \\
\text { caindo devido às } \\
\text { pesquisas }\end{array}$ \\
\hline $\begin{array}{l}\text { Aplicação } \\
\text { Principal }\end{array}$ & $\begin{array}{l}\text { Geração em } \\
\text { momento de } \\
\text { baixa ou } \\
\text { nenhuma } \\
\text { incidência de } \\
\text { luz solar }\end{array}$ & $\begin{array}{l}\text { Pico de } \\
\text { geração para } \\
\text { atender algum } \\
\text { pico de } \\
\text { demanda }\end{array}$ & $\begin{array}{l}\text { Geração em } \\
\text { momento de } \\
\text { baixa ou } \\
\text { nenhuma } \\
\text { incidência de luz } \\
\text { solar }\end{array}$ \\
\hline $\begin{array}{l}\text { Aplicação } \\
\text { Secundária }\end{array}$ & $\begin{array}{l}\text { Dessalinização } \\
\text { e processos } \\
\text { industriais }\end{array}$ & $\begin{array}{l}\text { Processos } \\
\text { industriais }\end{array}$ & $\begin{array}{l}\text { Dessalinização e } \\
\text { processos } \\
\text { industriais }\end{array}$ \\
\hline
\end{tabular}

\section{CONCLUSÃO}

Levando-se em conta o excelente potencial para geração de energia elétrica com o uso de termoelétricas CSP no semiárido brasileiro, onde tem-se localidade com disponibilidade de luz solar por até 10 horas por dia, e também o barateamento e aperfeiçoamento das tecnologias de armazenamento térmico, fica evidente a predisposição dessa região para esse tipo de investimento onde não só o país ganha, mas também o empresariado que investir nesse ramo do setor elétrico.

Destaca-se especialmente a região de encontro entre os estamos do Piauí, Pernambuco e Bahia. Região essa onde o Sol é abundante, há proximidade de vias públicas e aeroportos, é bastante irrigada por rios afluentes do São Francisco e encontra-se em estados que já têm a tradição da geração de energia renovável com as suas plantas eólicas.

Como sendo a forma de geração com maior eficiência, a torre solar é a opção certa para ser usada no semiárido. Por ser mais cara que as outras, pode ser que assuste os investidores. A segunda opção é a calha parabólica que já é muito usado no mundo, tem um preço mais em conta e também tem boa eficiência. Tecnologias como fresnel e disco parabólico devem ser evitadas por terem baixa eficiência e aplicação restrita respectivamente.

Por fim, no tocante ao armazenamento, o sal fundido apresenta-se como melhor opção por ter muita pesquisa sendo feita e já hoje ser uma realidade. No caso de se usar o sal fundido, é preferível que se use a tecnologia de tanque único que, embora demande ainda mais alguns estudos, é mais barata para ser instalada e tem um desempenho melhor que a tecnologia de dois tanques. Outra boa opção é o armazenamento usando concreto. O Brasil tem tradição em pesquisas com concreto, o que pode acabar sendo um fator muito favorável para a implantação dessa modalidade. O armazenamento Ruth não é uma boa opção por não poder suprir a carga por muito tempo, o que foge do propósito que é ter uma térmica despachável.

\section{REFERÊNCIAS}

\section{[1] EMPRESA DE PESQUISA ENERGÉTICA. Balanço Energético Nacional, 2017.}

\section{[2] INTERNATIONAL RENEWABLE ENERGY AGENCY. CONCENTRATING SOLAR POWER, Jun 2012.}

[3] CORREIA, R. C et al. A região semiárida brasileira. In: VOLTOLINI, T. V. (Ed.).

Produção de caprinos e ovinos no Semiárido. Petrolina: Embrapa Semiárido, 2011.

[4] PORFIRIO, A. S.; J. C. CEBALlOS, J. C. Validação da Estimativa de Irradiação Solar Direta Normal Por Satélites. In: CONGRESSO BRASILEIRO DE ENERGIA SOLAR, 5., 31 mar. - 03 abr 2014, Recife. Anais [...] Recife: OHMINI, 2014.

[5] PEDROSA, M. O.; MARIANO, V. Análise da Tendência da Irradiação Solar e Temperatura Ambiente no Agreste Nordestino Empregando Dados Medidos de Longo Prazo. In: CONGRESSO BRASILEIRO DE ENERGIA SOLAR, 7., 17-20 abr. 2018, Gramado. Anais [...] Gramado, RS: ABENS, 2018.

[6] SORIA, R.; SCHAEFFER, R.; SZKLO, A. Configurações Para Operação de Plantas 
Heliotérmicas CSP com Armazenamento de Calor e Hibridização no Brasil. Revista Brasileira de Energia Solar, v. 5, n. 1, p. 01-10, jul. 2014.

[7] SCHLIPF, D.; STENGLEIN, M.; SCHNEIDER, G. Thermal Storage CSP Technology: State of the art and market overview.Cooperação Alemã: GIZ/MCTI. Projeto Energia Heliotérmica, Brasília, 2014.

[8] RICHTER, C.; TESKE, S.; SHORT, R. Concentrating solar power, global outlook 09: why renewable energy is hot. Greenpeace. Amsterdam, 2009.

[9] ROSS, T. Thermal storage options for CSP, Set 2012 